\title{
HUMAN RIGHTS AND MEDIA: THE EXPERIENCE OF THE COMMISSION OF INQUIRY ON NORTH KOREA
}

\author{
Michael Kirby*
}

\begin{abstract}
Increasingly UN human rights mandate-holders are engaging with diverse modern media to enhance the effectiveness of their work. There are dangers and difficulties in doing so. However modern media can be a useful ally in the work of the UN by raising awareness of grave crimes and violations; engaging with and empowering victims of abuse; and encouraging demands that investigations will be followed by action and accountability. This article, based on the experience of the UN inquiry into North Korea explains the COI's methodology; examines the adoption and features of its media plan; outlines a number of suggested basic rules to be observed by UN inquiries; identifies modalities of news management; and predicts likely future developments inherent in new media technology. The author insists that news coverage is not an end in itself but a means to help attain the human rights goals of the inquiry and of the UN.
\end{abstract}

\section{MEDIA AND HUMAN RIGHTS: NATURAL BEDFELLOWS?}

Even in oppressive countries, those responsible for abuses of human rights normally perform their deeds of commission and omission in private, away from the glare of publicity. Publicity and news attention encourage supporters of global human rights to address the violations of human rights of peoples and individuals. They speak up and demand action. Secrecy is a cloak for terrible crimes and violations.

This is why, in the current international situation, those with responsibility for the United Nations' efforts to advance universal human rights, and to expose violators, have increasingly looked to the media (especially

\footnotetext{
* The Hon. Michael Kirby AC CMG, Former Chair of the United Nations Human Rights Council's Commission of Inquiry on North Korea (2013-14); former Special Representative of the Secretary-General of the United Nations on Human Rights in Cambodia (1993-6); one time Justice of the High Court of Australia (1996-2009).
} 


\section{HUMAN RIGHTS AND MEDIA: THE EXPERIENCE OF THE COMMISSION OF INQUIRY ON NORTH KOREA}

international media) to support their efforts. Between the time in the 1990s when I discharged a mandate as Special Representative of the SecretaryGeneral for Human Rights in Cambodia (1993-6) and the more recent time in which I served as Chair of the Commission of Inquiry (COI) on alleged human rights violations in the Democratic People's Republic of Korea (DPRK) (North Korea) (2013-14), ${ }^{1}$ I noticed a significant change in the engagement of United Nations personnel with the media. A connection with media became more intensive, more time consuming and more professional. Moreover, it is supported from the top of the Organisation. The SecretaryGeneral of the United Nations (Ban Ki-moon), the High Commissioners for Human Rights, other agency heads and mandate-holders have become much more willing to engage with media and much more skilful in doing so. By this I mean not only local newspapers, radio and television interviews but also international media and the new social networks, blogs, Reddit and the internet generally. Together these media can bring news, information and opinions of UN experts on human rights to an audience far wider than that which, in the past, had access to UN reports on human rights concerns.

There are, of course, dangers in such engagement. They include:

* The capacity of hostile media to distort, edit and manipulatively abbreviate interviews, so as to cast the United Nations and its officials in a bad light;

* The danger of media that has its own partial agenda and biased viewpoint that will distort the messages that the UN officials try to convey;

* The growth of opinionated journalists; superficial "celebrity" coverage of serious events; and the deliberate or negligent misrepresentation of news stories dealing with human rights problems. By definition, these problems are ordinarily serious and deserving of a careful reportage that respects complaining victims and is also fair and accurate towards alleged perpetrators; and

* The vicissitudes of modern media today include the priority given to personality, colourful celebrities and visual stories, particularly those designed to tug the heart strings or to enflame the passions of the audience. These can sometimes distort the stories themselves and influence competing priorities.

${ }^{1}$ Established by the United Nations, Human Rights Council, resolution 22/13, adopted 21 March 2013. 
These problems, which have become magnified over the past 20 years, were amongst the reasons why some early office-holders of the United Nations were suspicious of media and often inclined to keep their distance. Other problems arise from the varying skills of mandate-holders, including in their respective linguistic abilities, in coping with the pressures of media questioning, particularly in circumstances that are highly charged, sensitive and potentially dangerous. This article acknowledges the dangers and difficulties. However, it proceeds on the assumption that, used with care and skill, the modern media can become an important ally for the United Nations' efforts to uphold and defend universal human rights. This proposition will be illustrated by reference to lessons taught by the COI on North Korea.

\section{ESTABLISHMENT AND METHODOLGY}

The COI on DPRK got underway after 7 May 2013 when the President of the Human Rights Council (HRC) appointed Sonja Biserko (a human rights expert from Serbia) and myself (a former judge in Australia) to join the Special Rapporteur on DPRK, Marzuki Darusman (Indonesia), as members of the COI. I was designated to serve as the Chair.

The mandate given to the COI specified nine substantive areas upon which reports had been received by the United Nations of serious and widespread violations of human rights. By its resolution, the HRC urged the government of DPRK to cooperate fully with the COI's investigation; to permit the members of the COI unrestricted access to the country; and to provide them with all necessary information to allow the fulfilment of the mandate. However, the Ambassador of DPRK in Geneva immediately rejected the establishment of the COI. He indicated that DPRK would not cooperate. $^{2}$ This position was not altered in the course of the investigation. Accordingly, the COI was unable to extend its investigation to on the spot scrutiny of the situation of human rights in DPRK. This was an undoubted disadvantage. But just as, in national jurisdiction, it cannot be left to a party suspected of grave violations in the law to determine whether or not it will cooperate with a body lawfully created to conduct such investigations, so in international jurisdiction the non-cooperation of DPRK could not be allowed to deflect the COI from performing its duty.

At the end of the investigation, in a comment on the report of the COI, the representative of China expressed the view that, as the COI had not been able

2 Letter from DPRK dated 10 May 2013 to the President of the Human Rights Council. See report of the detailed findings of the Commission of Inquiry on Human Rights in the Democratic People's Republic of Korea, A/HRC/25/CRP.1 (7 February 2014), 8-9 [21]. 


\section{HUMAN RIGHTS AND MEDIA: THE EXPERIENCE OF THE COMMISSION OF INQUIRY ON NORTH KOREA}

to persuade the country concerned (DPRK) to cooperate, its report was necessarily flawed and deprived of essential evidentiary material and thus legitimacy. This cannot be the way in which the Charter of the United Nations is intended to operate. Effectively, such a view would give every state of the Organisation a veto power. Under the Charter, only the Permanent Members of the Security Council enjoy the exceptional power of an effective veto, and then only in validating defined decisions of the Security Council on non-procedural matters, in respect of which the concurring votes of the Permanent Members must be included in the majority outcome. ${ }^{3}$

Nevertheless, for reasons of ensuring a thorough, impartial and effective investigation, and to address the optics of the inaccessibility of the country and people most concerned, the COI addressed the issue of its methodology at its first meeting held in Geneva on 1-5 July 2014. It decided to advertise widely for submissions and to conduct public hearings before which witnesses for whom it would be safe, could provide oral testimony.

In the result, a large number of witnesses, including some institutional and some with special expertise, approached the Commission to give evidence. To meet the potential criticism that these witnesses were self-selecting and unacceptably prejudiced against DPRK, the COI decided, with the approval of the witnesses, to film the evidence and to place it online. Where it was judged to be unsafe or risky to do so, either the witness would be interviewed in confidential session and not filmed or photographed, or improvisations would be adopted (disguises of various kinds) to fulfil the mandate instruction to avoid any risks to the witnesses.

The foregoing decisions were to prove time consuming and demanding for the members of the COI and its secretariat, as for some witnesses. There were various logistical difficulties, including the necessity of translation of evidence and security for witnesses. However, the methodology adopted afforded the COI, where it accepted the witness testimony, an appropriate response to the charge of partiality. Critics and the merely curious could be invited themselves to view the witness testimony. In this way modern information technology, supported by the interest of international news media, brought the veracity question directly to the interested international audience. Because, overwhelmingly, the witnesses were plainly truthful and commonly impressive, the transparency adopted by the COI constituted an antidote to the criticisms levelled against it by DPRK and China.

Subsequent efforts of the COI, in cooperation with the governments of the Republic of Korea (South Korea) (ROK) and Japan, secured transcripts of the oral testimony. These were made available both in English and in the

${ }^{3}$ United Nations, Charter, 26 June 1945; 59 stat. 1031; TS 993, 3 Bevans 1153, entered into force 24 October 1945, Article 27.3. 
language in which the witness gave evidence. Like the digital images, these transcripts were later uploaded on the website of the COI.

In addition to these matters of methodology, the COI, in the spirit of transparency, also consulted the major national missions having an interest in the situation in North Korea: Australia, China, France, Laos, the Russian Federation, Thailand, the United Kingdom and the United States of America. Later, meetings in Geneva with regional participants from Africa, ASEAN, Europe and Latin America permitted outreach to most countries with a special interest in DPRK.

The conduct of public hearings in Seoul (20-24 August 2013); Tokyo (2930 August 2013); London (23 October 2013) and Washington DC (30-31 October 2013) produced a powerful body of testimony that became highly visible on several continents. Often the testimony was extremely vivid, dramatic and distressing. The manner in which the COI went about its task was therefore adapted to modern media: radio, television, print media, the internet and social media. If the medium in the contemporary world is to some extent the message, the methodology of the COI on DPRK projected a potent message of transparency. It demonstrated the impartiality of the commissioners, both in the way in which they gathered evidence by nonleading questions and in their assessment of the evidence itself as credible, reasonable and normally convincing, even understated. In this way, the methodology chosen by the commissioners re-enforced the success of the way in which the COI went about its work. It helped to neutralise the noncooperation of DPRK. It provided intensely powerful statements of apparent veracity. It also afforded the COI a pool of vivid evidence with which to illustrate its investigations of the nine subject areas nominated by the mandate from the HRC. In the subsequent write up of the report of the COI, it was therefore possible to include, effectively on every second page, quotations from the hearing transcripts. These allowed victims of grave human rights abuses to describe their ordeals in their own language. By quoting them, the COI gave them a voice to the highest levels of the United Nations and the international community. It also avoided the inevitable tendency of second and third hand versions of evidence to reduce the power of witness expositions by mediating them through the analysis and impressions of third parties, however expert.

Apart from every other utility of this source of evidentiary material, the technique of public hearings afforded to the media a large pool of expressive evidence, in direct speech, from which media could freely quote. In this way, the methodology of the COI was well adapted to the modern techniques of media reporting. Generally, these seek to concretise large, opaque issues by invoking the described experience and reactions of the named witnesses. 


\section{HUMAN RIGHTS AND MEDIA: THE EXPERIENCE OF THE COMMISSION OF INQUIRY ON NORTH KOREA}

\section{ADOPTING A MEDIA PLAN}

Although none of the Commissioners of the COI on DPRK was a journalist by training, each had viewed the operation of modern media in their own country. In my own case, a period of service as Chairman of the Australian Law Reform Commission in 1975-84 had given me the experience of working with national media to explain, justify and promote institutional recommendations for law reform. Accordingly, in my own country, 20 years earlier, I had a decade's experience of working with print and electronic media.

Further, during my service as Special Representative of the SecretaryGeneral for Human Rights in Cambodia, I had insisted on engagement with local, national and international media. At the end of each visit to Cambodia as Special Representative, a media conference was conducted. Even in the 1990s, this was the usual practice of human rights mandate-holders for the United Nations. ${ }^{4}$ This practice is an important aspect of transparency and free speech, which is itself a basic human right. However, it has to be handled with care to avoid needless criticism by the governments concerned, hostility, and allegations of bias and pre-judgment. The COI on DPRK was fully alert to these risks and it avoided them.

To ensure the availability of expert guidance in dealing with the media, the COI engaged for its visits to Seoul and Tokyo in August 2013, a journalist with extensive experience in the human rights work of the United Nations, $\mathrm{Mr}$ Ron Redmond, a United States national. At the request of the COI, he developed a media plan. This was basically adhered to throughout the work of the COI.

Mr Redmond was not available for the COI's public hearings in London nor subsequently. However, at that time, the COI secured the support and assistance of a senior officer in the Office of the High Commissioner for Human Rights (OHCHR), Mr Rolando Gomez. He also assisted the COI in relation to its engagements with the General Assembly ( $3^{\text {rd }}$ Committee) in October 2013 and later the "Arria Procedure" to brief members of the Security Council (17 April 2014). In addition, for engagements in Geneva, particularly with the HRC, side events in the Palais de Nations and with engagements with UN and independent news media in Geneva, the COI had the support and assistance of Mr Rupert Colville and Ms Liz Throssell. They helped arrange the media conferences that took place in Geneva at the time of the Oral Update of the HRC (September 2013), the release online of the English language version of the COI report (17 February 2014) and the formal

\footnotetext{
4 Ted Piccone, Catalysts for Change: How the UNs Independent Experts Promote Human Rights (Brookings Institution 2012) 23-24, 31-32, 116, 125.
} 
presentation of the report to the HRC and engagement with the HRC members and other nations (17 March 2014). The media conferences, and follow up media interviews in Geneva and the media 'stake out' in New York after the Arria Procedure in the UN Headquarters on 17 April 2014, were all very heavily attended by media. Each such engagement lasted more than an hour. Each was heavily reported in local and international print and electronic media, as well as in social media and on the internet.

The media plan initially, devised by Mr Redmond, involved a number of initiatives:

* Information Brochure: A number of frequently asked questions were addressed in detail. These contained clarifications of the mandate of the COI, expressed in language that could be picked up and used in media reports. It also included a description of what a COI was; what the mandate of the COI on DPRK provided; the history and background of the COI; the identities and short biographies of the commissioners; an analysis of the mandate; an outline of the immediate program of the COI; and some quotes that could be attributed to the commissioners in relation to the immediately pending public session of the COI;

* Media Releases: In advance of each series of public hearings and the other engagements in Geneva, Washington and New York, media releases were produced and widely distributed through the UN media contacts. These gave different angles on the work of the COI and on the purpose of the upcoming engagements. For the public hearings in Seoul and Tokyo, translations of the media releases into the local language were provided. This was also done in advance of subsequent important engagements of the COI;

* Interviews: A schedule of interviews was prepared and approved by the commissioners in advance of the engagements of the COI both for public hearings and also consultations in Geneva and New York. As well, indications were provided as to how additional interviews might be secured and contacts were given to permit direct enlistment of the help of the COI media officer.

* Embargos: Strict embargos were assigned to a number of engagements, including the oral updates in Geneva and New York in 2013, the initial release of the COI report to the media in February 2014; and the presentation of the COI report to the HRC and members of the Security Council, respectively, in March and April 2014. One 


\section{HUMAN RIGHTS AND MEDIA: THE EXPERIENCE OF THE COMMISSION OF INQUIRY ON NORTH KOREA}

international news service appeared to breach the embargo specified for the initial release of the report. This potentially endangered the impact of the primary release of the findings of the COI. Immediate efforts of the Geneva-based media officers circumvented what could have been a serious disturbance of the hoped-for impact of the COI report. In the result, as a sanction, the offending agency was excluded from the ensuing media conference in Geneva, although not without protests and excuses offered on its behalf.

* Social Networks: An officer of the Office of the High Commissioner for Human Rights (OHCHR) handles the release of human rights material on social networks, including Twitter, Weibo, You Tube, Reddit, blogs and other modalities. This expertise was enlisted to ensure maximum possible distribution of the COI's media material. The consequence was one of the most widespread and powerful examples ever of news coverage in the human rights field. Of course, the readability, attractions and significance of the COI report itself assisted in this endeavour. International news media is particularly discerning in the attention it gives to news stories. It is also resistant to attempts to "puff" news stories into a significance that they inherently lack. The widespread coverage of the successive stages of engagement of the COI on DPRK with news media was commented upon in many places, including in observations by senior officers of OHCHR. $^{5}$

* Follow up and Assessment: At my request, following the conclusion of his engagement with the COI, the initial media officer who formulated the media plan, Mr Redmond, prepared an assessment of the lessons and a description of the COI's media engagement. ${ }^{6}$ This assessment is candid. It addresses such issues as planning guidelines; the importance of local field support; the requirements of suitable venues for public hearings; the assessment of local interest; the possible necessity of procedures for registration of media; the handling of interview requests; the monitoring of media coverage; the conduct of post hearing media conferences; and the utilisation and

5 M Rishmawi, "The Role of Human Rights Fact Finding in the Prevention of Genocide”, unpublished paper for International Conference on Prevention of Genocide, Brussels, March 2014, referring at p 2 to the Commission on the Occupied Palestinian Territory and Southern Israel, 2009, (Judge Richard Goldstone, President).

6 Ronald Redmond, "Media Relations for COI Public Hearings in the Field: Lessons Learned from the COI on Human Rights in DPRK”, unpublished, OHCHR, 2013. 
archiving of video materials, transcripts and other records. The report also contains a number of useful recommendations for COIs of the United Nations Human Rights system in the future. Future suggested activities include the creation of dedicated websites for the COI on DPRK; the posting on them of electronic copies of the report of the COI; the inclusion of speeches of commissioners given in the course of the performance of their duties; transcripts of media conferences; news coverage; photographs and other materials. The posting of nonEnglish language media materials and of translations into other languages of the Report and Detailed Findings of the COI are imperatives to ensure the success of the $\mathrm{COI}$ in reaching out beyond a purely English language audience.

In what follows, a number of basic rules for the conduct of COIs will be mentioned. These have no official significance but are possibly useful indications for those who work in advancing the United Nations' cause of protecting and upholding human rights through the mandates given to bodies such as COIs and to individuals such as special rapporteurs as well as dedicated committees and agencies.

\section{SOME BASIC RULES}

* Maintaining a cool temper: Recently, when addressing a conference, the microphone system broke down for the third time. I protested somewhat bluntly in frustration. Whilst this was a natural human reaction, it was damaging to the message and looked inappropriate in the recording preserving the passing event for repeated viewings. Unerring patience is called for in all dealings with media, particularly where these activities are filmed or otherwise recorded;

* Clarification of context: Preferably before recording begins, It is important to clarify whether the interview is live or pre-recorded; on or off the record; will or will not be edited; and will or will not be open to correction and a fresh take if the interviewee is unhappy with the question or answer or conditions maintained during the interview. It will also be important to clarify any embargo that will be observed by the media, where that is required or desired;

* Personality, infotainment: Some modern media, as stated above, trivialise serious stories and reduce them to superficial or predictable images. Many questions were addressed to me concerning the emotional impact of the COI testimony of human rights abuses on me, 


\section{HUMAN RIGHTS AND MEDIA: THE EXPERIENCE OF THE COMMISSION OF INQUIRY ON NORTH KOREA}

personally. It is important to answer such questions honestly but briefly. Of course, the important issue is not the emotions of the COI member but (for crimes against humanity) the condemnation of the international community. However, a refusal to answer may seem over-proud. A well answered response may help to bring home to the audience the inevitable feeling of revulsion. It may give the response a concrete and personal edge that helps to convey the emotions which should be felt by viewers and listeners alike when confronted with certain evidence. However, the interviewee should not be misled into thinking that his or her reactions are significant in themselves;

* Time constraints: Modern media increasingly operates under time constraints shorter than was the case in earlier times. Sometimes this can be irritating, as where a question is asked and, in the midst of the answer, the interviewee is interrupted to be told "we must leave it there". The proper reaction is to attempt to wind up quickly and not to show irritation, however justifiable this might be. Interviewees must also learn to be brief. Often this is difficult for lawyers and other professional experts. They may know many complications and qualifications. But brevity is crucial to good media messaging;

* Bite size: In answering questions, it is best to provide communication in bite size chunks so that the questioner can get in more questions. Interviewers sometimes themselves have big egos and occasionally aspire to be, or become, "media personalities". Lawyers and other experts frequently see multiple ramifications and even potential traps in media questions. This does not provide a justification for longwinded answers, with multiple layers of qualification and elaboration. The primary rule is KISS: Keep It Simple Stupid, the message reportedly given to Hubert Humphrey, an unsuccessful US Presidential candidate, by his wife. It remains a good injunction. Presumably he did not follow it. He lost the election;

* Exhibiting calm: A good interviewee will remain calm, civil, polite and courteous at all times. This also exudes an image important for human rights. Universal human rights are expressed with the authority of the United Nations and international law. United Nations mandateholders can therefore afford to be calm. They deserve to be authoritative. They are speaking in support of an important and global cause in which they themselves can only ever be a temporary and minor player; 
* Cultural issues: It is essential to avoid discriminatory language or implications and to ensure respect for all relevant minorities and local cultures, at least so far as they conform to universal human rights. Naturally, local audiences will ordinarily be proud of their cultures, society, religions and values. Where these are criticised by a mandate holder, by reference to a norm of universal human rights, it should be done carefully, accurately and respectfully;

* Gender sensitivity: It is desirable that COIs undertake consultations with UN Women and, where possible, have a dedicated gender adviser who will scrutinise documents, including drafts for media reports and ensure attention to gender-specific issues and the avoidance of gender unfriendly language, patriarchal values or apparently insensitive appearances, attitudes or actions;

* Training and experience: After rudimentary training and opportunities to exercise their skills non-experts can become skilled in media presentation. It is desirable that COIs should have available to them experienced media advisers (as the COI on DPRK did for a time). Commonly, such advisers will remain present during interviews and offer constructive criticisms and comments for improvement of individual interview techniques and clarification of key messages. COI members, who may not have experience in media engagement, should not be embarrassed to ask for advice because such engagement is an increasingly important part of the work of human rights for UN COIs and other mandate-holders. Incompetence, arrogance, hot temper, needless politicisation, unprofessional behaviour, sexism, racism, homophobia, abuse of authority and other errors must be avoided. Media will often be vigilant and unhesitating in reporting such faults. On the other hand, if the COI has manifest integrity, is clearly striving to be impartial, truthful and compliant with principle, media will usually detect these features and be supportive. This is not universally so as some media outlets or individuals have their own agendas to pursue. But normally, the working journalist will have an interest in common with a COI or other mandate-holder. This is to get out a story that is brief, accurate and interesting. This is the motivation that COI members and their secretariats must engage with;

* Human interest: The methodology of much modern media is to avoid abstract concepts and to illustrate problems with human interest stories. Whilst this can sometimes be irritating and can result in superficial, personalised coverage of complex and serious issues and 
repeated use of particular stories, it is also a way of rendering human rights abuses concrete and understandable for ordinary readers, listeners and viewers. COI members must therefore consider the ways in which particular testimony (especially if there have been public hearings or other non-confidential interviews) can help illustrate large points being advanced by the COI. A strength of the report of the COI on DPRK derived from the fact that, on about half of the pages of the report, vivid passages are quoted from the public hearings or other interviews conducted by the COI that help to bring to life the suffering involved in human rights abuses. They do this in a way that dense text and detailed reporting might not do. Moreover, such quotes can be picked up and used later, in media releases, in oral television grabs and in print media reports. They will tend to be used, and so repeated, in syndicated news items, op eds and editorial opinions;

* Debriefing: At the conclusion of every day of work of the COI or other mandate holder's work in the field and in public outreach it is useful to engage in a debriefing exercise so that commissioners, in consultation with the secretariat and (if there is one) the media adviser can go through the events of the day; note the main messages that emerged from those events; and review how to express those messages more succinctly and effectively in the media messages that follow. This is also a time and opportunity for secretariat officers to correct any factual errors - however small - that may have crept into media statement and comments by the Commissioners. It is easy to feel irritated by such corrections. However, they are usually wellintentioned and designed to protect the mandate holder from immaterial attack based on factual errors or misstatements of the evidence; and

* News analysis: In addition to internal debriefing of the COI, it is desirable that assistance be provided to the COI (and other mandateholders) by way of follow up analysis of news coverage, descriptions of the "hits" on the dedicated COI/mandate website; and tweets and other social networks concerned with the COI or other mandates. A record should be kept, whether electronic or in print form, of media coverage so that this will become part of the chronological archives of the project. Such media coverage, particularly if online, helps those who come later to describe and analyse the conduct of the COI and to assess the success of its investigation. 


\section{MESSAGING AND NEWS MANAGEMENT}

In most societies, it is not ultimately possible for a COI to manage the presentation of, and priority given to, its media messages. News media are properly vigilant as to their own role in news selection and presentation. Nevertheless, a number of sensible rules may be observed that enhance the coverage of the desired news story:

* Variety and new material: The COI should decide for itself upon clear themes and messages. It should also continually vary some messages in order to avoid media fatigue that will be exacerbated by repetition of old news;

* Simple messages: It is highly desirable that messaging should be kept simple and avoid unduly complex issues of law, history and policy which may be of interest and importance to experts but of less concern to most journalists and consumers of news media. Excessive detail in media releases is likely to kill media interest in the COI once and for the future;

* Basic rules: It is usually best for commissioners to adhere to short sentences; to avoid the use of the passive voice; to stick to some clear and repeated messages; and, on the main themes of their work, to agree on language into which those messages should be packaged by the several COI members;

* Assertions: It can be useful, where it is the fact, to assert appropriately the observance by the COI of the principles of impartiality, independence, due process and procedural fairness and to illustrate these merits by reference to the activities of the COI which can be described. For example, the point was often made that a number of the witnesses giving oral testimony to the COI on DPRK insisted on their love for Kim Il-sung, the first member of the Kim family of Supreme Leaders of North Korea. This protestation was usually on indication of the honesty and neutrality of the witnesses. It tended to contradict the assertion by DPRK that the witnesses were "human scum" and hopelessly biased against the DPRK regime;

* Appearance: It is desirable for COI members and staff to attend to basic matters of appearance for television filming: combing the hair, fixing the tie or scarf, removing nasal hairs, dusting shoulders etc. 


\section{HUMAN RIGHTS AND MEDIA: THE EXPERIENCE OF THE COMMISSION OF INQUIRY ON NORTH KOREA}

These are simple matters but appearance is inescapably important in messaging in modern media, particularly visual media;

* Over familiarity: Some journalists seek to ingratiate themselves by assuming terms of familiarity. Generally, it is best for UN officers to avoid undue familiarity and the use of first names with media personnel at least whilst on film or radio interviews. Without becoming pompous or appearing self-important, it should be remembered that the issues of human rights are invariably serious and too much informality or the injection of inappropriate humour will not be considered correct by most readers, listeners or viewers; and

* Bullying: Some media employees may try to pressure or bully the interviewee. This can be politely rejected and deflected. Losing one's temper whilst being filmed is not a good look. Staying calm is imperative and it attracts admiration.

\section{GLOBAL MEDIA AND HUMAN RIGHTS}

Appreciation: Where media have helped a COI, the help should be reciprocated. In the case of the North Korea Inquiry, the earliest possible copies of the COI report were distributed to media on the day of release, subject to embargo. Special care was taken to supply journalists who had accurately reported the hearings and activities of a COI. Where media advisers have helped the COI, their help should be acknowledged both to them and to their superiors and drawn to the notice of the High Commissioner for Human Rights. The days of regarding media as an enemy to United Nations' operations are over. Especially in the discharge of human rights mandates, media can be influential in spreading the awareness of human rights abuses; alerting those concerned about the existence of a mandate and where to contact the mandate-holder(s); informing the world community of the steps taken to expose and redress serious wrongs; and raising expectations that perpetrators of human rights abuses everywhere will be rendered accountable, both before the Human Rights Council and in follow up before appropriate institutions of international criminal justice.

Reports: The advances in the technology of contemporary media make it appropriate to envisage changes in the format future of HCR reports. Already such reports, available online, permit links to be made to earlier reports and other relevant sources of information. In the future it may be anticipated that access will also be provided to victim statements, graphic photographs and moving film; and statistical and like data displayed in attractive format. Reports quoting victims will become multimedia in character and permit the 
victims to speak, directly, not mediated through the analysis of reporters. An application by the COI on DPRK to the Human Rights Council to supplement the textual/oral presentation of its oral report to the HRC with digital images containing the voices of victims recorded at its public hearings was declined by the Presidency. The Presidency expressed concern about potential misuse of such technology. This risk can perhaps be understood. However, because most media communication today has become multimedia, it must be expected that reports to the HRC will eventually follow suit.

Mobilising the enlarged potential: It behoves all, who are engaged in the work of human rights and with the OHCHR, to use the potential of new technology of media more effectively. In this, I believe that High Commissioner Pillay (HCHR) gave a particularly important lead. So, I believe, did the COI in DPRK.

Mobilising social media: Officers of OHCHR are now available to advise commissioners (typically of a different generation) concerning the potential of social media to expand and enlarge access to human rights mandate reports. These can reach large and different, usually younger, audiences. They also require new styles of reporting, in terms that are briefer and sharper, with much less patience for detail.

Blogging and Tweets: Some present and future COI members may be tempted to blog or tweet their personal opinions about their work. Some such messaging may not always have been sufficiently thought out. Care must be observed to avoid showing prejudgment or breaching due process requirements by revealing provisional COI deliberations out of due order or accidentally breaching security. Nevertheless, because many younger people secure news and information today through these means, they will undoubtedly come to play a significant part: informing interested persons about the COI or other mandate, its activities and impressions, wherever permissible. If necessary, mandate holders should seek, and obtain, professional assistance from inside the Office of the UNHCHR on how to use new media and how to avoid the pitfalls.

Availability of Commissioners: COI commissioners and other mandate holders should be available, and not hostile, to modern media. High Commissioner Pillay was particularly skilful in using global media. She thereby enhanced the worldwide awareness of the work of her Office and of the independent mandate-holders who report to the HRC.

\section{PROBLEMS OF AVAILABLITY}

Because of the often intense work of the COI, the long hours, in some cases working in a foreign language, and the pressures of responsibility, engagement with the media may sometimes slip to the bottom of the list. 


\section{HUMAN RIGHTS AND MEDIA: THE EXPERIENCE OF THE COMMISSION OF INQUIRY ON NORTH KOREA}

However, this attitude should be resisted because of the potential, properly performed, for media engagement to enhance and re-enforce, and not detract from, the work of the COI. A number of simple rules can be used in engagements with the media:

* Attitudes: It is important not to regard the media as an enemy or hostile competitor. In rare cases hostility may exist or eventuate. But generally, media have an interest in common with the UN officers: to spread knowledge about the work; to encourage cooperation; to raise visibility; and to promote expectations of successful and practical outcomes;

* Deadlines: Particular difficulty is often presented by media deadlines. These arise every day and at differing times of the day. COI members must, so far as they seek to interest and mobilise media, be conscious of deadlines and of their frequent inflexibility. They must strive to work within the realities of media deadlines. So far as is consistent with the fulfilment of the mandate, a COI should strive to release and embargo media releases with such deadlines in mind;

* Competition: Media interests will often be in competition. Care must therefore be taken to observe even-handedness, to avoiding "favourites" and to engage with all media on the basis of equality, courtesy and mutual respect;

* Embargoes: It is important for any embargo on the publication of a media report to be made completely clear, including by reference to relevant international time zones. Likewise, it is vital to be clear where speaking to the media is "off the record" or by way of "background" only. Generally such limited communications should be minimised. A COI should operate transparently and honourably; and this generally means speaking and acting on the record when both parties to the briefing know precisely what material is available for quotation and broadcast. Confidential information will require protection. Great care must be taken to safeguard the identity and evidence of confidential witnesses. Their safety and even their lives may depend on it;

* Photographs: It is desirable that good quality photographs of the Commissioners should be available and provided by the secretariat or media officer to media interests; 
* Informal photographs: Media will often seek informal photographs or film showing the COI at work. Care should be taken to check any surrounding personnel or witnesses; background images and potential embarrassments;

* Media officer: Wherever possible, a dedicated media officer (or OHCHR media personnel) should be engaged to assist the COI and to propose successive cycles of media releases and interviews for consideration by the commissioners as the work of the COI unfolds;

* Establishing website: A dedicated website for the COI should be established soon after its establishment. Onto this website should be posted regular updated materials concerning the program and activities of the COI; and

* Variety of voices: It is desirable that a variety of voices for the COI should be heard. This will involve deflection of particular questions at a media conference, for example, so that all Commissioners become identifiable and bring their several interests and talents into play. Diversion of questions to other commissioners should be carried out, preferably with their prior concurrence. In the presentation of the oral report of the COI on DPRK to the Arria briefing of the Security Council on 17 April 2014 in New York, the course was adopted of dividing the oral remarks so that each Commissioner spoke. This ensured that a variety of voices was heard. It relieved the potential monotony of a single voice. It demonstrated the unity, and also any special interests, of the COI members. In particular, in the case of the COI on DPRK, it allowed the highly responsible role of women in the COI's work to be clearly demonstrated.

\section{CONCLUSION: BENEFICIAL SYMBIOSIS}

I pay a tribute to the Commissioners and secretariat of the COI on DPRK for their industry, adaptability and willingness to innovate in relation to media engagement. The COI demonstrated clearly that no country today can pull down the shutters and prevent the scrutiny of its human rights record by the United Nations, simply by refusing to cooperate. A commission of inquiry today may cross even the most hostile border. It may negotiate the loftiest prison walls and bring the message of human rights abuses to the notice of the world through global news media and the internet. Nowadays, as was said in the context of DPRK, no one has an excuse to say they do not know of human rights abuses brought to light by the United Nations. Now we all know. And 


\section{HUMAN RIGHTS AND MEDIA: THE EXPERIENCE OF THE COMMISSION OF INQUIRY ON NORTH KOREA}

that knowledge propels us to seek to address, and to demand, accountability: justly, effectively and quickly.

It is still too early to judge the success of the COI on DPRK. All of the Commissioners insisted that success was not to be assessed simply by reference to the provision of a report, however well written and widely covered. Success depends on positive outcomes on the recommendations made by the COI: an improvement in the human rights situation for the people of Korea; an enhancement of cooperation by the state concerned with the OHCHR, the HRC, the General Assembly and the Security Council; and greater knowledge and understanding of the situation in DPRK in the wider world. Judged by these criteria the COI on DPRK chalked up a number of achievements. Several of these lay in the context of engagement with the media. The full story is yet to be written. 